\title{
ANÁLISE ECONÔMICA DAS DECISÕES JUDICIAIS NOS CONTRATOS DE SEGURO
}

\section{ECONOMIC ANALYSIS OF JUDICIAL DECISIONS IN INSURANCE CONTRACTS}

\begin{abstract}
ANNE CAROLINE WENDLER
Especialização em Especialização Lato Sensu em Direito Aplicado pela Escola da Magistratura do Estado do Paraná(2008), especialização em Gestão de Direito Empresarial pela FAE Business School(2012), especialização em Direito Contratual de Empresa pelo Centro Universitário Curitiba(2017) e especialização pela Pontifícia Universidade Católica do Paraná(2008). Atualmente é Advogada da Rücker Curi Advocacia e Consultoria Jurídica.
\end{abstract}

\section{OBJETIVOS DO TRABALHO}

O objetivo do presente resumo expandido é refletir como as decisões judiciais nos contratos de seguro podem alterar a oferta de serviços securitários e formação dos prêmios, gerando os chamados custos de transação, para os demais integrantes do grupo que são usuários desse tipo de contrato e que não figuraram na demanda judicial. O tema é relevante, porque o Poder Judiciário, vinculado às regras, define quais serão aplicadas, quando podem ou não ser violadas, abrindo exceções para a sua quebra por determinados agentes, e criando incentivos tanto positivos quanto negativos, às pessoas seguirem ou não as determinações desse jogo, inclusive com relação aos contratos ${ }^{1}$.

\footnotetext{
${ }^{1}$ TIMM, Luciano Benetti; ALVES, Francisco Kümmel. Custos de transação no contrato de seguro: proteger o segurado é socialmente desejável? Manaus: CONPEDI - Conselho Nacional de Pesquisa e Pós-Graduação em Direito, 2007, p. 03.
} 
Personalidade Acadêmica Homenageada:

Carlos Aurélio Mota de Souza (Universidade Ibirapuera - UNIB)

\section{METODOLOGIA UTILIZADA}

O estudo utilizará o método de pesquisa quantitativa e qualitativa. A pesquisa quantitativa no que se refere à apresentação de eventuais dados sobre receita e provisões técnicas apurados no mercado de seguros. A pesquisa qualitativa no que se refere ao entendimento doutrinário e jurisprudencial dos Tribunais Estaduais e Superior Tribunal de Justiça, que servirão de relevante subsídio para reflexões sobre a temática.

\section{REVISÃO DE LITERATURA}

A existência do contrato de seguro demonstra o receio natural do homem a qualquer lesão, perda patrimonial ou a mera expectativa de perda. Este receio que provoca a cooperação mútua para o rateio de custos para a manutenção de um fundo capaz de arcar, financeiramente, com os prejuízos de um sinistro, denominado seguro.

A mutualidade é suporte econômico essencial em toda a operação de seguro, onde cada um contribui com uma pequena parcela, proporcional à sua parte no risco, criando uma quantia de dinheiro para suportar os prejuízos que alguns dos componentes do grupo sofrerão. Aliado à noção do mutualismo está a técnica estatística que, conforme aduzido por Pedro Alvim, é o cálculo das probabilidades de ocorrência de riscos, que estabelece a relação entre o número de casos verificados e o número de chances possíveis².

A Análise Econômica do Direito (AED) tem sido utilizada para compreender questões relacionadas à macroestrutura dos sistemas jurídicos e aos incentivos dos atores que agem dentro do sistema. No caso do seguro, a Análise Econômica do Direito (AED) pode demonstrar como decisões judiciais são capazes de afetar a formação dos prêmios, a médio e no longo prazo e, é sob esse enfoque que será realizada a análise do comportamento do Judiciário frente aos contratos de seguros.

\footnotetext{
${ }^{2}$ ALVIM, Pedro. O Contrato de Seguro. $2^{\mathrm{a}}$ ed. Rio de Janeiro: Forense, 1986, p.4.
} 
Personalidade Acadêmica Homenageada:

Carlos Aurélio Mota de Souza (Universidade Ibirapuera - UNIB)

Segundo estatísticas do Conselho Nacional de Justiça (CNJ) há no Brasil 80 milhões de processos, sendo que, em 2016 foram registrados 860.245 novas ações de seguro. Somente em São Paulo, há 20 milhões de processos, destes, 212.297 são do setor, registrados no ano em 2016.

Uma das funções desempenhadas pela Superintendência de Seguros Privados - SUSEP (autarquia vinculada ao Ministério da Fazenda) é aprovar as cláusulas gerais de contratos de adesão das seguradoras, para que somente então estas passem a utilizá-las na contratação com os segurados. Ocorre que a interpretação de tais cláusulas ou a sua informação imperfeita são o motivo recorrente das disputas judiciais, a exemplo das cláusulas restritivas de cobertura.

Inicialmente poderia se questionar que se a cláusula foi previamente aprovada pela SUSEP, haveria de se considerá-la válida. Ocorre que no direito contratual brasileiro a liberdade contratual é mitigada em razão da tutela do consumidor, que acaba por afastar as disposições que se afigurem abusivas sob a ótica do Judiciário, seja porque retiram a razão de ser do próprio contrato de seguro, seja em razão da assimetria informacional.

De fato, há necessidade da tutela do consumidor, todavia, resta determinar o sentido das decisões judiciais que, em algumas hipóteses, no Brasil, tendem a premiar o hipossuficiente, no caso o segurado.

Pergunta-se: Consumidor brasileiro é vulnerável, hiper-vulnerável e hipossuficiente sempre? Ou será que na atual sociedade de informação e tecnologia, pode-se inferir a existência de uma escala de consumidores? Como cumprir o dever de informação consagrado no art. 6을 III do CDC, se o consumidor não quiser se informar?

Haveria que se reconhecer a existência de um mínimo que se espera que todo consumidor compreenda a partir de um volume de informações disponibilizadas pelo fornecedor. No entanto, ao que parece perante o Judiciário, é positivo para o consumidor se declarar não informado, porque isso the garante maior proteção.

A título de exemplo, não obstante a ingestão bebida alcóolica seja hipótese de infringência ao Código de Trânsito Brasileiro, as decisões judiciais acerca da responsabilidade da seguradora, para pagamento dos danos causados por acidente 


\section{Personalidade Acadêmica Homenageada:}

\section{Carlos Aurélio Mota de Souza (Universidade Ibirapuera - UNIB)}

de trânsito no qual o segurador está embriagado, não refletem a vedação do Código de Trânsito Brasileiro.

O Judiciário, valendo-se da norma protetiva do Código de Defesa do Consumidor, em geral, impõe que para aplicação da cláusula de exclusão de cobertura por agravamento de risco - por ingestão de álcool -, seja necessária a comprovação do nexo de causalidade entre o acidente e a alcoolemia.

Certamente se o Judiciário firmasse o entendimento de que a mera comprovação da ingestão de álcool implicaria na perda do direito ao recebimento da cobertura securitária, uma vez que vedação à condução de veículo automotor sob influência de álcool é amplamente difundida junto à população; culminaria na redução do prêmio cobrado aos segurados e, contenção do risco moral destes, uma vez que passariam a ser mais cautelosos.

Timm observa que o Judiciário brasileiro, abarrotado de casos e defronte uma legislação com ampla margem interpretativa derivada do modelo solidarista, acaba se limitando ao caso individual e sem pensar nos efeitos de segunda ordem de seus julgados. ${ }^{3}$

A indenização máxima que o segurador deverá pagar não poderá exceder o montante de tal interesse, devendo o Judiciário impedir que o seguro se transforme em fonte de ganhos indevidos, evitando determinar o pagamento do seguro, quando inexistente a cobertura, a fim de evitar o comportamento oportunista (risco moral).

Outrossim, reportando-se ao exemplo acerca do agravamento de risco por ingestão de álcool estar condicionado ao nexo de causalidade com o acidente, verifica-se certa tendência das decisões judiciais não acompanharem a intensão do legislador - no caso em comento, o art. 165 do Código de Trânsito Brasileiro ${ }^{4}$-, ao mesmo tempo em que alteram o custo de transação do contrato de seguro, ensejando o aumento do prêmio do contrato de seguro.

\footnotetext{
${ }^{3}$ TIMM, Luciano Benetti; ALVES, Francisco Kümmel. Custos de transação no contrato de seguro: proteger o segurado é socialmente desejável? Manaus: CONPEDI - Conselho Nacional de Pesquisa e Pós-Graduação em Direito, 2007, p.15.

${ }^{4}$ Art. 165 . Dirigir sob a influência de álcool ou de qualquer outra substância psicoativa que determine dependência:

Infração - gravíssima; Penalidade - multa (dez vezes) e suspensão do direito de dirigir por 12 (doze) meses.
} 
Personalidade Acadêmica Homenageada:

Carlos Aurélio Mota de Souza (Universidade Ibirapuera - UNIB)

\section{RESULTADOS OBTIDOS OU ESPERADOS}

A partir do estudo da Análise Econômica do Direito (AED), verifica-se que o Poder Judiciário desempenha papel relevante no desenvolvimento econômico da atividade securitária, trazendo consequências quanto aos custos de transação no mercado de seguros.

Segundo Timm, cada vez mais, reflexo da tendência de justiça social distributiva presente no direito privado brasileiro, inúmeros são os julgados que colidem com aquela lógica quantitativa e atuarial do seguro, nos quais se responsabilizam seguradoras a cobrir sinistros não originariamente previstos em apólices de seguro (mesmo contra a letra clara do contrato). ${ }^{5}$

Segundo Eros Grau, a decisão judicial implica, inarredavelmente, emoção e violação, visto que o juiz decide sempre dentro de uma situação histórica determinada, participando da consciência social de seu tempo. ${ }^{6}$

No âmbito securitário, a decisão do magistrado que concede o pagamento de seguro quando inexistente a cobertura, pode servir de incentivo a práticas oportunistas e, por conseguinte, implicar no surgimento de distorções.

Evidentemente que não se desconhece que existem abusividades de cláusulas contratuais e assimetria informacional que devem ser corrigidas pelo Poder Judiciário. Todavia, o que se pretende na presente análise é abordar os casos em que o julgamento se dá contra qualquer ilegalidade do contrato e intenção do legislador, que acaba por gerar os chamados custos de transação e prejudicar a mutualidade de segurados, ao fundamento de que se deve tutelar o consumidor.

\footnotetext{
${ }^{5}$ TIMM, Luciano Benetti; ALVES, Francisco Kümmel. Custos de transação no contrato de seguro: proteger o segurado é socialmente desejável? Manaus: CONPEDI - Conselho Nacional de Pesquisa e Pós-Graduação em Direito, 2007, p.3.

${ }^{6}$ GRAU, Eros Roberto. Por que tenho medo dos juízes? (a interpretação/aplicação do direito e os princípios). 7ª . ed. São Paulo. Malheiros. 2016, 75.
} 
Personalidade Acadêmica Homenageada:

Carlos Aurélio Mota de Souza (Universidade Ibirapuera - UNIB)

\section{TÓPICOS CONCLUSIVOS}

A análise econômica tem sido utilizada para compreender questões relacionadas à macroestrutura dos sistemas jurídicos e aos incentivos dos atores que agem dentro do sistema. Como atores centrais de qualquer sistema jurídico, os juízes são, compreensivelmente, foco da análise comparativa. A independência do Judiciário tem sido o foco de alguns importantes trabalhos empíricos. ${ }^{7}$

Nesse cenário, a proposta do presente resumo expandido é refletir sobre as decisões do Poder Judiciário, que no âmbito dos contratos securitários ao aplicar o Código de Defesa do Consumidor, acaba em certa medida chancelando atitudes oportunistas, concedendo cobertura em situações em que não havia previsão contratual.

Embora seja possível fazer cálculo atuarial para tal situação, a saber: embriaguez ao volante, a fim de se identificar quanto um consumidor deva pagar de prêmio no contrato de seguro do seu automóvel na hipótese de se envolver num acidente de trânsito quando embriagado, fato é que não é desejável socialmente que essa cobertura de seguro seja realizada.

Sob a ótica do consumidor é difícil compreender que alguns riscos são seguráveis e outros não são seguráveis. Aliás, mesmo quando se trata de risco seguráveis, há que se avaliar os riscos impróprios de serem protegidos, a exemplo da embriaguez na condução de veículo, assunto ainda controvertido perante o Poder Judiciário, que acaba por gerar os chamados custos de transação, para os demais integrantes do grupo que são usuários desse tipo de contrato.

\section{REFERÊNCIAS}

ALVIM, Pedro. O Contrato de Seguro. $2^{\text {a }}$ ed. Rio de Janeiro: Forense, 1986, p.4.

\footnotetext{
${ }^{7}$ TIM, Luciano Benetti (organizador). Direito e economia no Brasil. $2^{\mathrm{a}}$ ed. São Paulo: Atlas, 2014, p. 148.
} 
Personalidade Acadêmica Homenageada:

Carlos Aurélio Mota de Souza (Universidade Ibirapuera - UNIB)

BRASIL, Lei 9. 503 de 1997, Código de Trânsito Brasileiro. Disponível em: www2.camara.leg.br/legin/fed/lei/1997/lei-9503-23-setembro-1997-372348-normapl.html. Acesso em 30 mar. 2018

GRAU, Eros Roberto. Por que tenho medo dos juízes? (a interpretação/aplicação do direito e os princípios). $7^{\text {a }}$. ed. São Paulo. Malheiros. 2016, (p. 75).

TIMM, Luciano Benetti (organizador). Direito e economia no Brasil. $2^{\text {a }}$ ed. São Paulo: Atlas, 2014, p. 148.

; ALVES, Francisco Kümmel. Custos de transação no contrato de seguro: proteger o segurado é socialmente desejável? Manaus: CONPEDI Conselho Nacional de Pesquisa e Pós-Graduação em Direito, 2007, p.3. 